\author{
ANNA JASIŃSKA \\ MuZeum Uniwersytetu JagiellońsKiego \\ KRAKÓw
}

\title{
PORTRET TRUMIENNY NIEZNANEGO ORMIANINA POLSKIEGO
}

W zbiorach Muzeum Uniwersytetu Jagiellońskiego w Collegium Maius w Krakowie znajduje się pięć portretów trumiennych. Niewiele wiemy o ich pochodzeniu. Hipotetycznie można przyjąć, że zostały przekazane przez profesora Mieczysława Gębarowicza ze Lwowa po drugiej wojnie światowej i zmianie granic Polski w wyniku nowych rozstrzygnięć politycznych. Gębarowicz przesyłał do Krakowa prywatnymi kanałami wybrane obiekty, by trafiły w bezpieczne miejsce, w ręce dziedziców tej kultury, która je wytworzyła.

Jeśli chodzi o portrety trumienne, w Collegium Maius znalazły się: portret trumienny Dosyteusza (Dymitra Baryły), metropolity mołdawskiego (suczawskiego), który zmarł na wygnaniu w Polsce, w Żółkwi, 13 grudnia 1693 roku ${ }^{1}$ (MUJ, nr inw. 6376, olej, blacha miedziana, wym.: 46 x $55 \mathrm{~cm}$ ); portret trumienny Mikołaja Nestorowicza Krasowskiego, zmarłego w 1697 roku działacza prawosławnej Stauropigii i właściciela kamienicy Nestorowiczowskiej we Lwowie ${ }^{2}$ (MUJ, nr inw. 5459, olej, blacha cynowa (?), wym.: 43 x $53 \mathrm{~cm}$ ); portret trumienny nieznanego Ormianina, datowany na drugą połowę XVII wieku (MUJ, nr inw. 6375, olej, blacha miedziana, wym.: $32,5 \times 33 \mathrm{~cm}$ ); portret trumienny nieznanego szlachcica, XVII wiek (MUJ, nr inw. 5457, olej, blacha cynowa, wym.: 42 x $42 \mathrm{~cm}$ );

1 Ф. Абрамов, Митрополит сучавский Досифей, „Журнал Московской Патриархии", 1974, 3, s. 50-52. Dosyteusz został kanonizowany w 2005 roku przez rumuński Kościół prawosławny. Jego krakowski wizerunek jest niemal nieznany w literaturze historycznej i hagiograficznej mu poświęconej.

${ }^{2}$ F. Jaw orski, O szarym Lwowie, Lwów 1916, s. 73-74. 
portret trumienny nieznanej kobiety, XVII/XVIII wiek (MUJ, nr inw. 5458, olej, blacha cynowa, wym.: $31 \times 29 \mathrm{~cm}$ ). Portrety dwóch pierwszych osób (metropolity Dosyteusza i Krasowskiego) zostały wymienione w katalogu wystawy Gdzie Wschód spotyka Zachód ${ }^{3}$ - jeden i drugi pochodziły z dawnych, lwowskich zbiorów Muzeum Instytutu Stauropigialnego, oba z adnotacją w katalogu: „zaginiony". O dwóch ostatnich portretach nie mamy żadnych informacji.

Portret „nieznanego Ormianina” nie posiadał klarownej identyfikacji, nawet przypisanie ormiańskości osobie na nim uwiecznionej nie miało żadnych podstaw, poza lakoniczną notką na odwrocie i w ślad za tym w inwentarzu muzealnym, pozbawioną autora. Dopiero porównanie z wizerunkiem, który pojawił się na wystawie zabytków ormiańskich, zorganizowanej we Lwowie w 1932 roku w siedzibie Archidiecezjalnego Związku Ormian przy ul. Ormiańskiej, dostarczyło danych, które pozwalają zasadniej powiązać sportretowaną postać z ormiańskością. Skromny katalog wystawy lwowskiej, opracowany przez polskich historyków sztuki ormiańskiej i wydany we Lwowie ${ }^{4}$, nie zawiera fotografii tego akurat eksponatu. Znajduje się tam tylko wzmianka, że w pierwszej sali wystawowej były pokazane portrety „nieznanego mężczyzny i kobiety [...] z trumien”'. Znacznie lepiej zilustrowana relacja Bronisławy Wójcik-Keuprulian, zamieszczona w paryskim czasopiśmie literackim, artystycznym i naukowym „U\{uuhhu” (Anahit), wydawanym przez wybitnego intelektualistę ormiańskiego Arszaga Czobaniana,

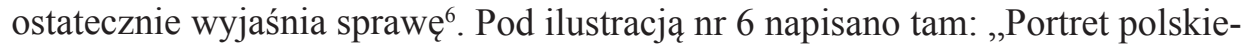
go Ormianina wykonany za życia, zdjęty z trumny"7. Ponadto w tekście znajduje się krótka wzmianka na temat interesującego nas wizerunku: „w tym prawdopodobnie pochodzące z XVII w. [portrety], przedstawiające kobietę (nr 5) oraz mężczyznę (nr 6), który nie jest nam znany"».

Trumienny portret Ormianina powstał w drugiej połowie XVII wieku. Jest sześcioboczny, malowany na miedzianej blasze. Przedstawia mężczyznę w układzie popiersiowym, typowym dla portretów trumiennych. Wygląd, to jest fryzura, wąsy i widoczny fragment ubioru - okrycie koloru czerwonego z futrzanym koł-

${ }^{3}$ Gdzie Wschód spotyka Zachód. Portret osobistości dawnej Rzeczypospolitej 1576-1763, katalog wystawy Muzeum Narodowego w Warszawie, red. J. Malinow ski, Warszawa 1993, s. 393-394, poz. 327, s. 412-413, poz. 407.

4 Wystawa zabytków ormiańskich we Lwowie 19.6-30.9.1932: przewodnik, red. A. Czołowski przy współpracy Ł. Charewiczowej, M. Gębarowicza, B. Wójcik-Keupruljanowej, T. Mańkowskiego, R. Miękickiego, Lwów 1932.

5 Ibidem, s. 16.

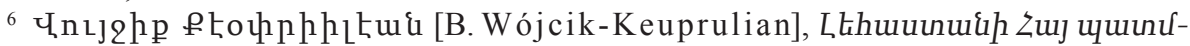

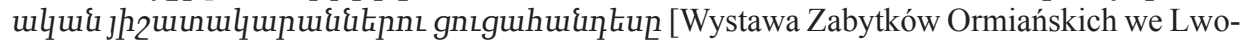
wie czerwiec-wrzesień 1932 roku], „Uquuhhun” [Anahit], 1932/1933, 3-6, s. 38-53 (wersja elektroniczna: tert.nla.am/archive/NLA\%20AMSAGIR/Anahit_paris/1932/5-6.pdf).

7 Ibidem, s. 42, il. 6, tłum. Jakub Osiecki.

8 Ibidem, s. 46. 
nierzem - nawiązuje do siedemnastowiecznych przedstawień mieszczan, którzy nosili się na wzór polskiej szlachty. Popiersie zostało umieszczone na złotym tle. Portret otacza repusowana w tym samym kawałku blachy miedzianej bordiura ze złoconym motywem roślinnym, tworząca jednocześnie ramę przedstawienia. Całość utrzymana jest w tonacji ciepłych brązów i ugrów. Biorąc pod uwagę strój portretowanego, ozdobną bordiurę oraz rodzaj blachy, można wnioskować, że mamy do czynienia z zamożną osobą, zapewne znaczącą w życiu publicznym. Na odwrocie przedstawienia widnieje stara naklejka $z$ informacją: „Portret niewiadomego / rzekomo jakiegoś Ormianina lwowskiego / Zdjęty z trumny, na blasze mal[owany]. Wiek XVII”. Dopiski: „B.31”, nieczytelne skreślenia.

Konterfekt trumienny stanowi unikatową formę portretu, charakterystyczną dla obszaru kultury nazywanej potem sarmacką, obejmującej tereny dawnej Rzeczypospolitej polsko-litewskiej. Do najstarszych należy wizerunek Stefana Batorego, zmarłego w 1586 roku, przymocowany pierwotnie do trumny króla9 oraz portret Adama Sędziwoja Czarnkowskiego ${ }^{10}$. Zwyczaj malowania portretów trumiennych przyjął się powszechnie w pierwszej połowie XVII wieku, a w wieku XVIII, w dobie oświecenia, powoli zanikał. Jak podaje Stanisław Wiliński, prawdopodobnie ostatnim portretem trumiennym jest wizerunek ks. Marcina Parczyńskiego, zmarłego w 1809 roku, znajdujący się w zbiorach Muzeum Diecezjalnego w Sandomierzu ${ }^{11}$. Portret trumienny powstawał głównie na blasze: ołowianej, cynowej, miedzianej, żelaznej, sporadycznie srebrnej, rzadko na podłożu drewnianym. Malowany (najczęściej) ${ }^{12}$ ad vivum bądź też kopiowany z wizerunków ad vivum, mocowany był na trumnie w zależności od jej kształtu, a więc dopasowywany do jej przekroju. $\mathrm{W}$ trakcie pogrzebu spełniał konkretną funkcję: przypominał osobę zmarłą, głosił jego chwałę. Poprzez często niemal werystyczne odtworzenie modela uczestnicy pompa funebris mogli mieć wrażenie fizycznej obecności zmarłego, który wręcz na nich patrzył. Zdarzało się, że w trakcie pogrzebu portret był zdejmowany z trumny i zawieszany na którejś ze ścian kościoła.

Wyobrażenia trumienne popularne stały się nie tylko wśród katolików. Moda ta objęła też społeczności prawosławne i protestanckie w dawnej Polsce. Spora liczba tego typu zabytków zachowała się na Pomorzu i zachodnich ziemiach Polski - głównie w Poznańskiem i Lubuskiem. Obecnie Muzeum w Międzyrzeczu posiada najliczniejszy zbiór portretów trumiennych w Polsce ${ }^{13}$.

9 S. Wiliński, U źródet portretu staropolskiego, Warszawa 1958, s. 33-34.

${ }^{10}$ P. Mrozowski, Siste gradum viator: o upamiętnieniu zmarlych w sztuce dawnej, w: Przeraźliwe echo trąby żałosnej do wieczności wzywajacej. Śmierć w kulturze dawnej Polski od średniowiecza do końca XVIII wieku, katalog wystawy w Zamku Królewskim w Warszawie, red. P. Mrozowski, Warszawa 2000, s. 77.

${ }_{11}$ S. Wiliński, Uźródel, s. 34.

12 J. Dziubkow a, Portret epitafijny i trumienny, w: Gdzie Wschód spotyka Zachód, s. 36.

13 J. Patorska, Portrety trumienne, tablice inskrypcyjne i herbowe. Katalog zbiorów Muzeum w Międzyrzeczu, Międzyrzecz 1996. 
Nic więc dziwnego, że i Ormianie sięgnęli po ten element obrzędowości staropolskiej. Na wspomnianej już wystawie lwowskiej prezentowano jeszcze dwa ormiańskie portrety trumienne. Poza „nieznaną kobietą” ormiańską, był tam jeszcze wizerunek Krzysztofa Roszki Bogdanowicza, kupca i wójta nacji ormiańskiej w Stanisławowie, zmarłego w 1767 roku $^{14}$, potem reprodukowany kilkakrotnie, przechowywany obecnie we Lwowskim Muzeum Historycznym ${ }^{15}$. Portretowany był osobą zamożną i łożył ofiarnie na potrzeby Kościoła ormiańskokatolickiego. Powstały aż dwa jego wizerunki trumienne, ofiarowane po pogrzebie do kościoła św. Mikołaja w Kamieńcu Podolskim i do kościoła w Stanisławowie. Również gmina ormiańska w Kamieńcu Podolskim wytworzyła tego typu obiekty. Znane są stamtąd portrety Mikołaja Czaykowskiego, wójta kamienieckiej nacji ormiańskiej, zmarłego w 1762 roku, i jego małżonki Zofii z Krzysztofowiczów, zmarłej w 1768 roku $^{16}$. Oba przechowywane są obecnie w zbiorach Państwowego Muzeum Historycznego w Kamieńcu Podolskim. Wydaje się, że właśnie Stanisławów i Kamieniec były tymi ośrodkami ormiańskimi, w których omawiana tu forma upamiętnienia zmarłych była popularna. W zbiorach polskich krakowski portret nieznanego Ormianina jest jedyną pamiątką tego typu, zachowaną z bogatego dziedzictwa kulturowego polskich Ormian.

Ponieważ eksponaty prezentowane na lwowskiej wystawie w 1932 roku przeznaczone były do projektowanego Archidiecezjalnego Muzeum Ormiańskiego, które tworzono przy arcybiskupstwie ormiańskokatolickim we Lwowie ${ }^{17}$, należy przyjąć, że jest to kolejny eksponat $\mathrm{z}$ tej kolekcji, obecnie rozproszonej, jeden z nielicznych znajdujących się na obecnym terytorium Polski.

\section{Bibliografia}

(Abramow) Абрамов Ф., Митрополит сучавский Досифей, „Журнал Московской Патриархии", 3, 1974, s. 50-52

Gdzie Wschód spotyka Zachód. Portret osobistości dawnej Rzeczypospolitej 1576-1763, katalog wystawy Muzeum Narodowego w Warszawie, red. J. Malinowski, Warszawa 1993

Jaworski F., O szarym Lwowie, Lwów 1916

Mrozowski P., Siste gradum viator: o upamiętnieniu zmartych w sztuce dawnej, w: Przeraźliwe echo traby żatosnej do wieczności wzywajacej. Śmierć w kulturze dawnej Pol-

14 Wystawa zabytków ormiańskich, s. 16.

15 Ostatnio w: Portrety polskich Ormian, kalendarz ścienny na rok 2016, k. [2], wyd. Fundacji Kultury i Dziedzictwa Ormian Polskich w Warszawie.

${ }^{16}$ Reprodukcja w: Portrety polskich Ormian, kalendarz ścienny na rok 2014, k. [5], wyd. Fundacji Kultury i Dziedzictwa Ormian Polskich w Warszawie.

17 J. T. Petrus, Archidiecezjalne Muzeum Ormiańskie we Lwowie, w: B. Biedrońska-Słota, Ormianie polscy: odrębność i asymilacja, katalog wystawy w Muzeum Narodowym w Krakowie, Kraków 1999, s. 27-32. 
ski od średniowiecza do końca XVIII wieku, katalog wystawy w Zamku Królewskim w Warszawie, red. P. Mrozowski, Warszawa 2000

Patorska J., Portrety trumienne, tablice inskrypcyjne i herbowe. Katalog zbiorów Muzeum w Międzyrzeczu, Międzyrzecz 1996

Petrus J. T., Archidiecezjalne Muzeum Ormiańskie we Lwowie, w: B. Biedrońska-Słota, Ormianie polscy: odrębność i asymilacja, katalog wystawy w Muzeum Narodowym w Krakowie, Kraków 1999, s. 27-32

Portrety polskich Ormian, kalendarz ścienny na rok 2014 i 2016, wyd. Fundacji Kultury i Dziedzictwa Ormian Polskich w Warszawie

Wiliński S., U źródet portretu staropolskiego, Warszawa 1958

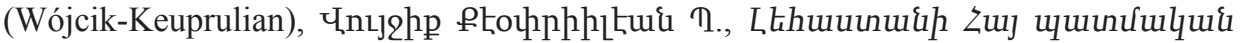
Jh2unulqupuifitpns gnıguhuintup [Wystawa Zabytków Ormiańskich we Lwowie czerwiec-wrzesień 1932 roku], „U\{uuhhun” [Anahit], 3-6, 1932/1933, s. 38-53 (wersja elektroniczna: tert.nla.am/archive/NLA\%20AMSAGIR/Anahit_pa ris/1932/5-6.pdf)

Wystawa zabytków ormiańskich we Lwowie 19.6-30.9.1932: przewodnik, red. A. Czołowski przy współpracy Ł. Charewiczowej, M. Gębarowicza, B. Wójcik-Keupruljanowej, T. Mańkowskiego, R. Miękickiego, Lwów 1932

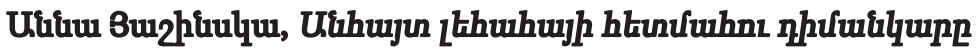

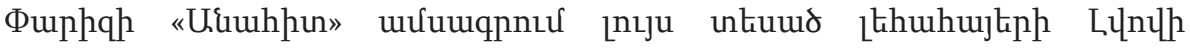

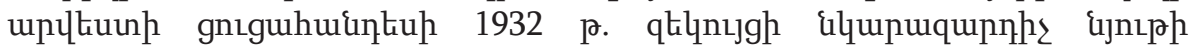

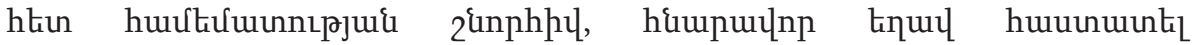

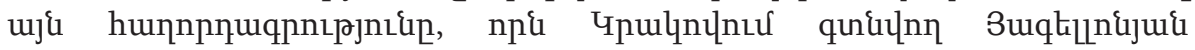

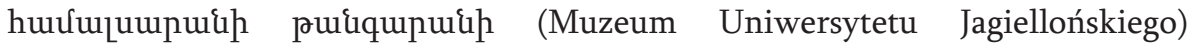

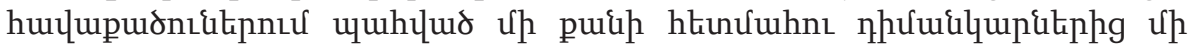

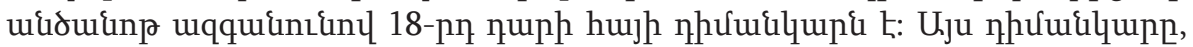

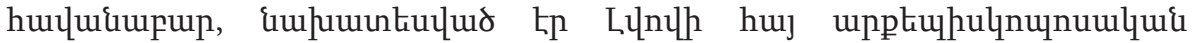

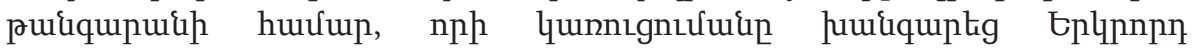

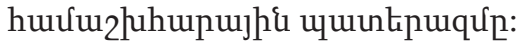

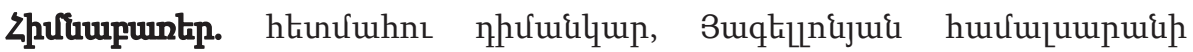

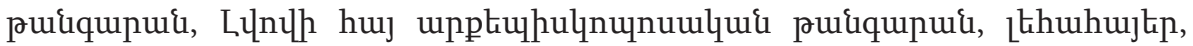
«Uiuuhpin»

\section{Anna Jasińska, Coffin Portrait of an Unidentified Polish Armenian Man}

The comparison between the illustrative materials and the report from the 1932 Lwów (Lviv) exhibition of Polish Armenian art that was published in the Paris magazine U\{uuhhun made it possible to confirm that one of the several coffin portraits held in the collections of the Jagiellonian University Museum in Krakow is an $17^{\text {th }}$ century portrait of an unidentified Armenian man. The portrait was most prob- 
ably intended for the Archdiocesan Armenian Museum in Lwów (Lviv), but the outbreak of the Second World War interrupted the plans to establish this institution.

Keywords: coffin portrait, Jagiellonian University Museum in Krakow, Archdiocesan Armenian Museum in Lwów, Polish Armenians, Uquuhpun 


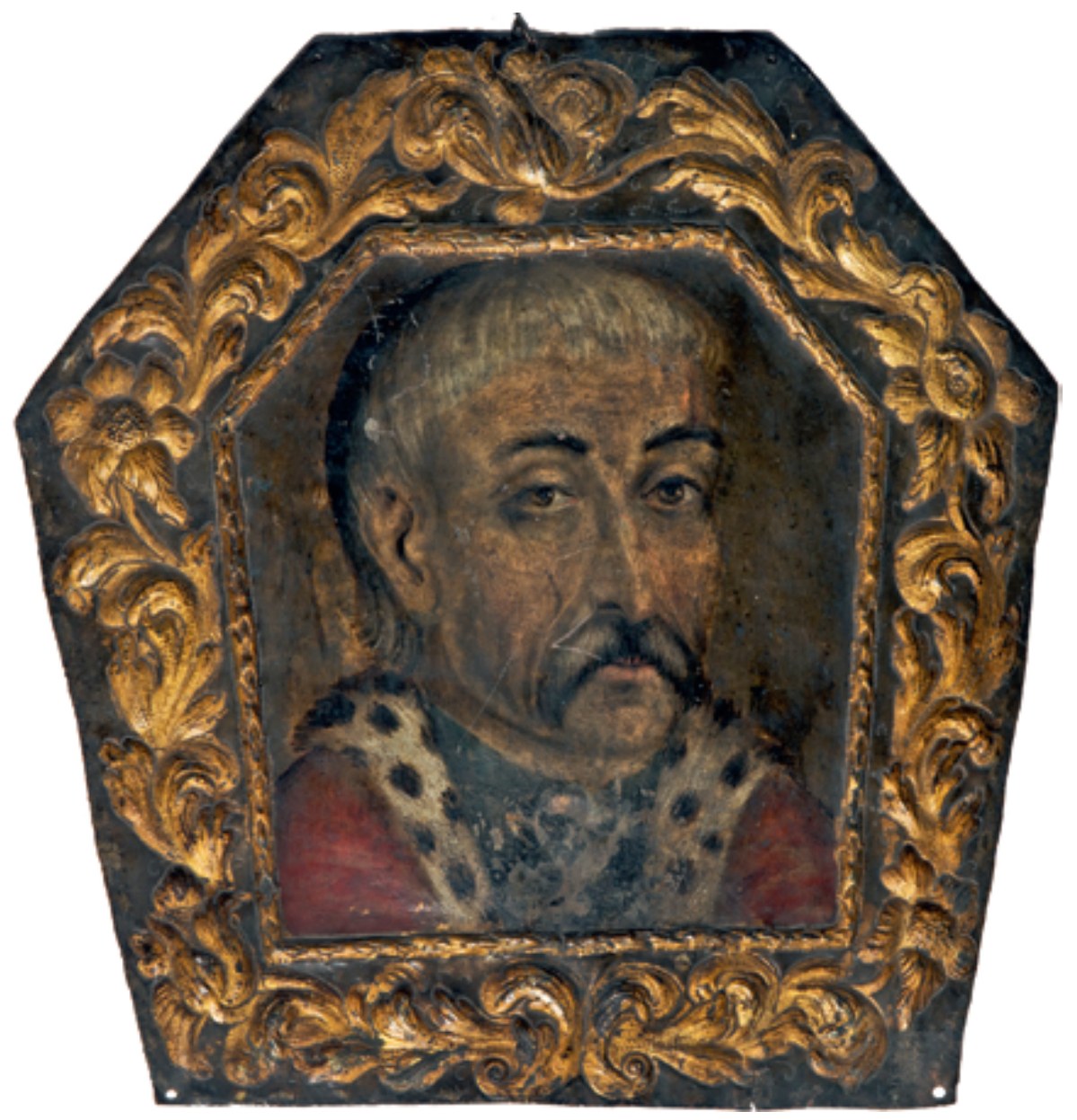

Portret trumienny nieznanego Ormianina, 2. poł. XVII w., Muzeum Uniwersytetu Jagiellońskiego, nr inw. 6375, olej, blacha miedziana 


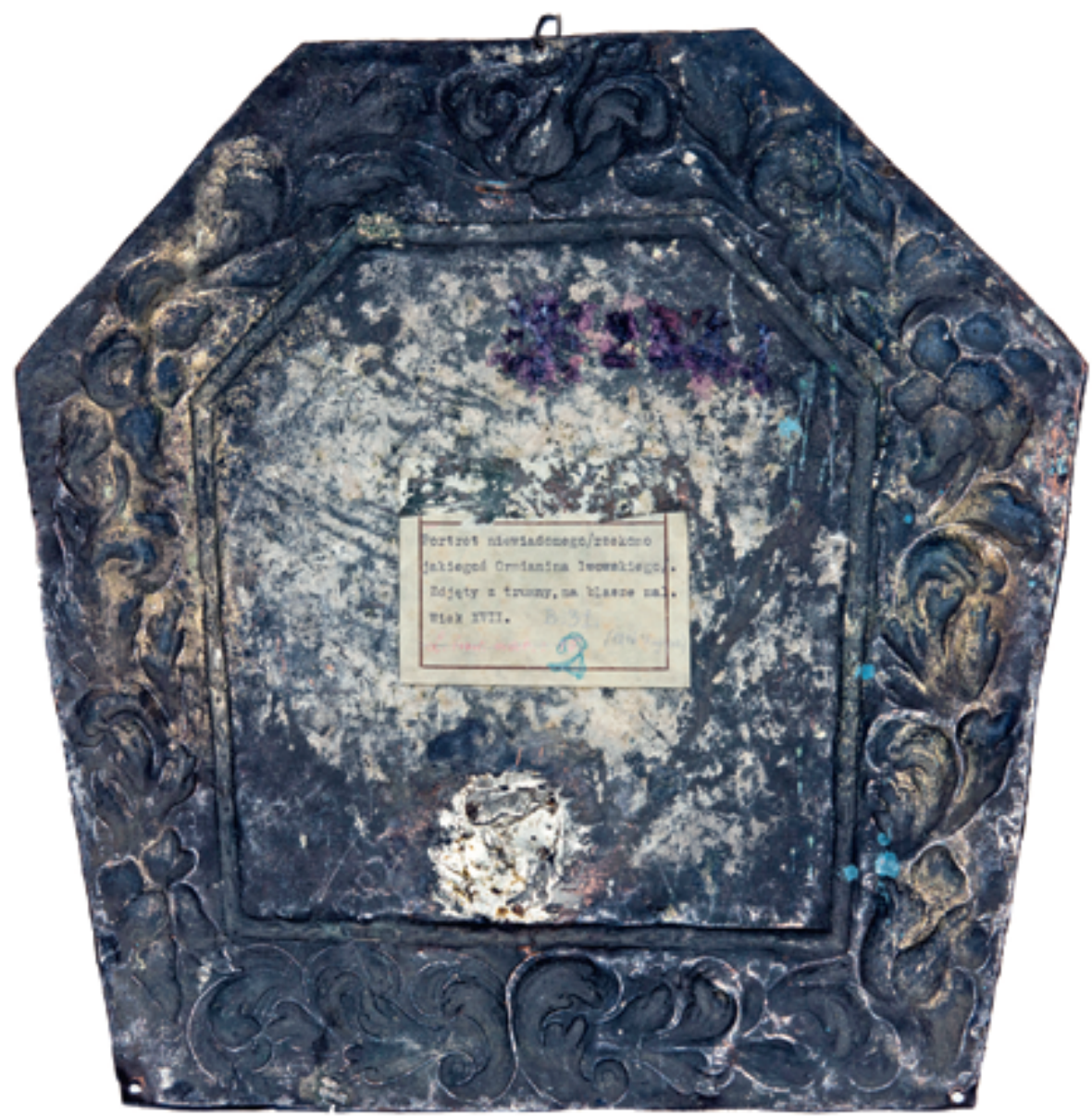

Odwrotna strona portretu nieznanego Ormianina, Muzeum Uniwersytetu Jagiellońskiego 